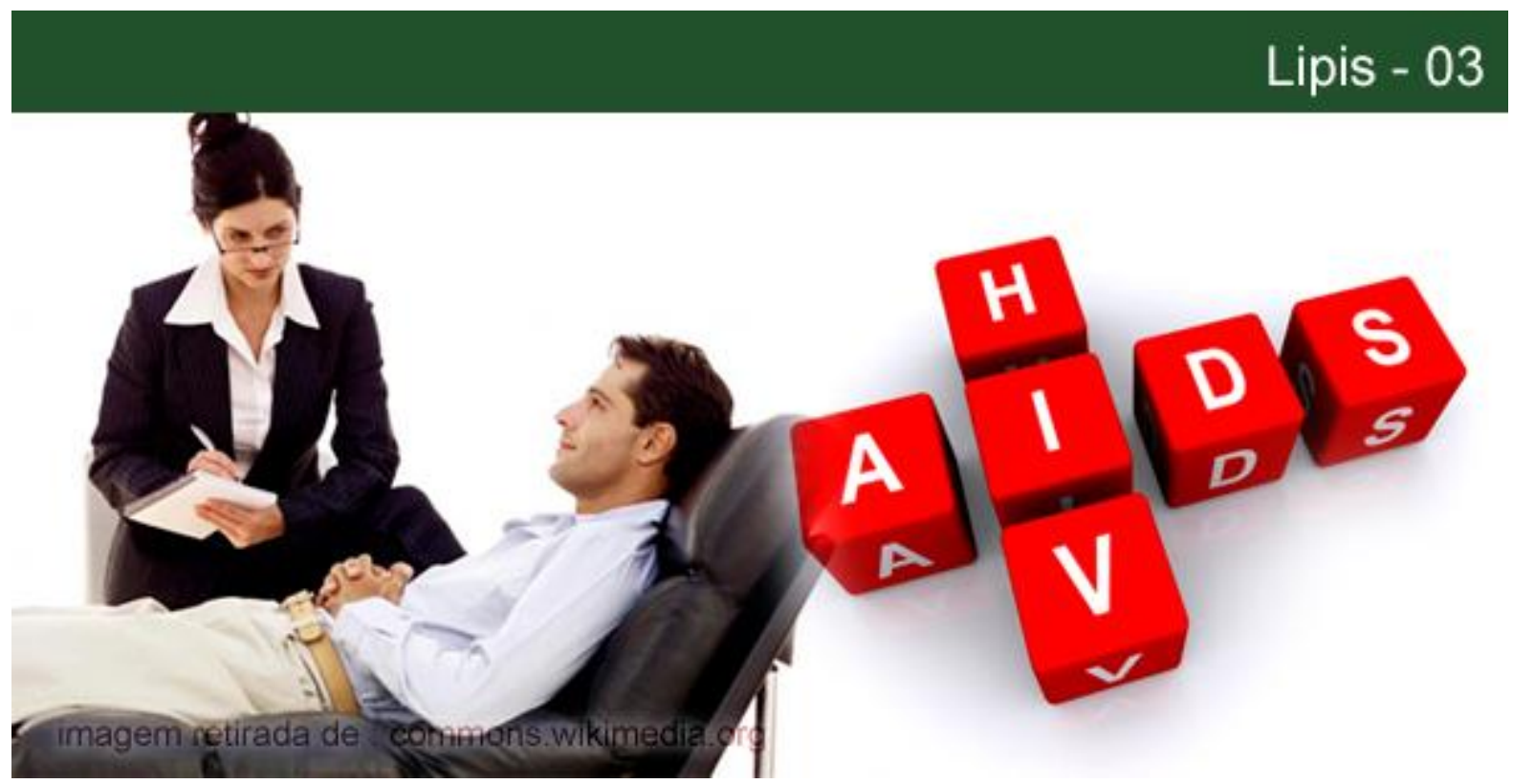

\title{
TRAVESSIAS ENTRE O PULSIONAL E O TRAUMÁTICO A PARTIR DA ESCUTA NA CLINICA DA AIDS
}

\begin{abstract}
Alessandro Melo Bacchini
Doutor em Psicologia Clínica pela Pontifícia Universidade Católica (PUC-Rio). Especialista em Psicologia da Saúde/Hospitalar pelo Instituto de Ensino e Pesquisa em Psicologia (IEPS). Membro do Laboratório de Psicanálise e Psicopatologia Fundamental (LPPF - Belém/PA) e pesquisador associado do Laboratório Interdisciplinar de Pesquisa e Intervenção Social (LIPIS/PUC-Rio). E-mail: ambacchini@yahoo.com.br.
\end{abstract}

\section{Alexandre Théo de Almeida Cruz}

Mestre em Psicologia Clínica e Social pela Universidade Federal do Pará (UFPA). Psicólogo Efetivo do Ministério Público do Estado do Pará. Coordenador Técnico da Fazenda da Esperança Nossa Sra de NazaréBelém/PA. Pesquisador associado do Laboratório Interdisciplinar de Pesquisa e Intervenção Social (LIPIS/PUC-Rio).E-mail: theo.cruz@hotmail.com.

Resumo: $\mathrm{O}$ artigo tem como objetivo discutir a noção de trauma em sua interseção com a segunda teoria pulsional. Tomando como eixo condutor pacientes que vivem a dolorosa experiência quando se sabem portadores de AIDS, os autores apontam a importância da compreensão da dinâmica traumática na escuta psicanalítica.

Palavras chave: Trauma. Pulsão. Aids. Psicanálise.

\section{CROSSINGS BETWEEN DRIVE AND TRAUMA WHEN LISTENING AIDETIC PATIENTS IN THE PSYCHOANALYTIC CLINIC}

Abstract: The article aims to discuss the concept of trauma in its intersection with the second drive theory. Taking as the main axis patients who live the painful experience when they discover they are infected with AIDS, the authors point out the importance of understanding the dynamics in traumatic for a more accurate psychoanalytic listening.

Keywords: Trauma. Pulsion. Aids. Psychoanalysis.

\section{POLÊM!CA $\mid$ LABORE (}

Polêmica - Revista Eletrônica da Uerj - Rua São Francisco Xavier, 524, $1^{\circ}$ andar bloco D, sl.1001 • Tels.: +55 21 2334-4088/4087 • http://www.e-publicacoes.uerj.br/index.php/polemica/index http://www.labore.uerj.br • laboreuerj@yahoo.com.br 
Em uma manhã de rotina, em um hospital voltado para pacientes portadores de HIV, presenciamos a seguinte cena: ao chegar ao leito da paciente, a médica responsável pelo atendimento apenas pronunciou estas palavras: "sabe aquele teste que eu falei? Pois é, eu fiz e deu positivo. Você está com aids e vai ter que se tratar [...]”. Durante este árduo enunciado, a paciente diz: "Meu Deus, eu tenho aids? Espera, eu não entendi (Silêncio). Olha, eu não consegui ouvir nada do que você está falando". Após isso, a paciente perde momentaneamente o controle dos esfíncteres e chega a desmaiar.

Esta situação relatada parece ser um correlato do que se propõe aqui analisar. A paciente escuta, mas ao mesmo tempo não escuta. Mas, como escutar de ouvidos limpos uma notícia como essa? E, além disso, da forma como ocorreu? Com esse excesso provocado pelo diagnóstico, como seria possível dar algum sentido? Qual efeito produzido por este diagnóstico pode ser descrito quando parece que a única saída possível para a paciente em questão, fora a de rejeitar, ao mesmo tempo em que aceita essa dura realidade a partir de um duplo de seu Eu: eu sei/eu não sei?

Tais questionamentos devem ser convertidos nesse momento para o entendimento da noção de trauma aqui empregada, pois importantes interlocuções teóricas podem dar uma tonalidade menos obscura a esta problemática.

O presente trabalho busca aprofundar a discussão acerca da questão traumática tomando como eixo condutor a sua relação com a pulsão. Para tal, discutiremos inicialmente a concepção de trauma para, em seguida, fazermos uma breve revisão da discussão da pulsão a partir da segunda teoria pulsional. Interessa-nos seu caráter de repetição objetivando uma melhor compreensão do atendimento a pacientes que viveram eventos traumáticos, no trabalho em pauta, pacientes diagnosticados com AIDS.

\section{Comentários sobre a teoria do trauma: da teoria da sedução à etiologia das neuroses}

De um modo geral, quando se discute a teoria Freudiana acerca do trauma, remonta-se aos primórdios do desenvolvimento técnico e teórico da psicanálise, levando em consideração tão debatida teoria da sedução sexual infantil e posterior desenvolvimento metapsicológico acerca da psicogênese da neurose. No entanto, importantes avanços teóricos sobre o conceito de trauma têm sido desenvolvidos para dar conta de uma prática clínica em que novos

\section{POLÊM!CA $\mid$ LABORE}


desafios são lançados a cada momento. Para tanto, torna-se necessária uma breve retomada da evolução metapsicológica do termo.

Em meados de 1890, Freud e Breuer, ao estudarem a histeria, estavam de acordo que sua cura se daria por recordar e relatar um evento traumático a partir do tranze hipnótico. Esta teoria inicial é considerada pré-psicanalítica: sustentava o método catártico embora já admitisse ideias inconscientes expressas nos sintomas, mas que eram levadas em conta apenas a partir da histeria e de outros casos psicopatológicos (RUDGE, 2009).

De acordo com Rudge (2009), ambos os autores sustentavam, para tanto, a teoria da dissociação e do afeto estrangulado, embora discordassem em pontos essenciais, elaborados a partir de um questionamento: por que a memória do trauma é dissociada?

Breuer sustentava a hipótese de que a memória do trauma havia sido dissociada porque o evento ocorrera durante um "estado hipnoide" (tal como pesquisava Charcot ao estudar a sugestão hipnótica em pessoas sugestionáveis em analogia a indivíduos acometidos por algum trauma) no qual haveria, além de uma predisposição a estes estados, uma capacidade prejudicada de associação de ideias e reação a acontecimentos traumáticos (RUDGE, 2009).

Já Freud, afastando-se nesse momento da medicina e da neurofisiologia, entendia que a memória do acontecimento traumático era dissociada porque "provocava angústia, na medida em que entrava em conflito com ideais ou desejos importantes para aquela pessoa. A dissociação obedecia, assim, ao propósito de defender o sujeito de um conflito psíquico" (RUDGE, 2009, p. 17-18).

Em Viena, no final do século XIX, a repressão sexual era bastante rígida, sobretudo em relação à educação destinada à mulher, o que torna-se um fator essencial para a ênfase de Freud na relação entre o trauma e o sexual. Isso o leva a caracterizar o trauma psíquico, que estaria na origem da neurose, como um trauma sexual precoce: a sedução da criança por um adulto. Questionava-se, no entanto, como tal experiência somente teria repercussão tão longínqua, o que leva Freud a desenvolver a noção de "a posteriori”. Tal noção, que fora explorada por Lacan em grande contribuição para seu entendimento, revela uma causalidade diferente da habitual (linear), mas uma relação constante entre acontecimentos presentes e o passado do desenvolvimento do indivíduo (RUDGE, 2009).

\section{POLÊM!CA $\mid$ LABORE}


Com o avanço da discussão sobre o trauma psíquico presente na própria origem da neurose, muito se avança na superação da noção sugerida nas primeiras obras freudianas, do trauma ligado à sedução precoce, como violências sexuais exercidas por um adulto. $\mathrm{O}$ debate sobre a sedução e sobre a natureza do trauma desloca-se aos poucos da discussão se seria algo do campo da fantasia ou da realidade, pois a releitura realizada por Freud ao levar em consideração a realidade psíquica como campo próprio da psicanálise, permite que se dê atenção fundamental à fantasia, sem desconsiderar os fatos. Com isso, a fantasia entra em cena mesmo em casos onde algo da realidade pode ser encontrado no que tange à sedução, não para ofuscar este dado, mas para que as análises não se resumam ao mero realismo simplista (RUDGE, 2003).

Por outro lado, é de se levar em consideração que a teoria do trauma infantil pode restringir o alcance teórico e clínico que cada vez mais têm sido convocados a se posicionar diante de demandas emergentes. Com isso, a discussão deve ser ampliada e não ser restringida apenas ao sentido do trauma infantil de natureza sexual.

Ao abordar os sintomas neuróticos, a literatura psicanalítica tem destacado essencialmente um sentido clássico do trauma infantil: remontá-lo ao conflito entre as forças defensivas e a fantasia - na ordem do sexual, pulsional e conflitivo -, por esta poder representar o abandono, a perda de amor, a punição e a castração. No entanto, busca-se no momento, tomar um caminho diferente e que permita uma maior aproximação ao sofrimento presente em pacientes contaminados pelo HIV/Aids.

\section{O trauma doloroso}

Deve-se analisar melhor o trauma - não relacionado apenas à sexualidade infantil - a partir deste momento justamente por sua atualidade na clínica. Esta versão do trauma é presente na teoria Freudiana a partir dos casos traumáticos do pós-guerra, que tinham caráter acidental e aparentemente não portavam relação com objetos sexuais. Para tanto, é interessante retornar à Conferência XVIII em que Freud (1916) analisa A fixação no trauma.

Inicialmente, Freud interpreta a fala de duas pacientes em análise que parecem estar fixadas em eventos de seu passado, permanecendo presas na doença, sem possibilidade de viver um estado presente ou futuro em suas vidas. A primeira das pacientes havia abandonado seu casamento na vida real, mas em sua vida anímica, por meio dos sintomas (não assinar seu

\section{POLÊM!CA $\mid$ LABORE}


nome, não conseguir dar presentes ou não cuidar de sua aparência física), continuava a se manter fiel ao marido em movimentos que mostravam que ela não podia entregar nada seu a ninguém (FREUD, 1916/1972).

A segunda paciente, por uma relação erótica com o pai e cronologicamente anterior à puberdade, produzia sintomas que ao mesmo tempo a impediam de se relacionar com outros homens e a mantinha presa a essa ligação com o pai. Freud considera essa manifestação, algo que se repete em toda neurose. Afirma que cada uma das pacientes analisadas fora conduzida a períodos bastante remotos de sua vida, próximos mesmo ao período de lactante. A analogia mais próxima que pôde se estabelecer a essas condutas neuróticas fora as neuroses traumáticas produzidas no período de guerras ou em outras situações alarmantes envolvendo grandes riscos para o indivíduo (FREUD, 1916/1972).

As neuroses traumáticas não são, em sua essência, a mesma coisa que as neuroses espontâneas comumente tratadas pela análise, segundo Freud, e até então ele afirma não encontrar uma aproximação satisfatória com seu ponto de vista sobre a doença. No entanto, ele afirma insistir em um aspecto em comum entre elas (FREUD, 1916/1972).

A raiz da neurose traumática é fixada no momento do acidente traumático, pois os pacientes repetem a situação traumática em seus sonhos como ataques histeriformes, como se o paciente sempre estivesse enfrentando a situação traumática. Freud ressalta nisso o caminho do aspecto econômico dos processos psíquicos afirmando que o termo traumático não possui outro sentido que não o econômico (FREUD, 1916/1972).

Por esta analogia, Freud analisa que poderia haver uma causa única para a neurose, a saber, a fixação (tal como na doença traumática) em experiências com tonalidades afetivas tão intensas que revelariam uma impossibilidade de apreensão pelo indivíduo - primeira tese elaborada em conjunto com Breuer (1893/1895). Esta concepção, se enquadraria bem à primeira paciente a qual Freud se remete, mas ele adverte a inadequação à segunda paciente, pois a relação afetuosa entre um pai e uma filha não é condição suficientemente necessária para se configurar um trauma, e além disso, na história da paciente em questão, a neurose somente se instalou depois da puberdade e não no momento do trauma (FREUD, 1916/1972).

Vemos como Freud tem seu foco voltado a dar conta dessa nova clínica que o convoca, pois há uma análise aqui na busca de dar conta de algo bastante novo, em relação à teoria geral das neuroses. Como afirma Rudge (2003), sua perplexidade não cessa e faz com

\section{POLÊM!CA $\mid$ LABORE}


que ele apresente em 1918, no $5^{\circ}$ Congresso Internacional de Psicanálise em Budapeste, uma tentativa de unificação entre as teorias sobre as neuroses de transferência e suas novas constatações sobre as neuroses de guerra. Nas palavras de Freud (1919/2010):

\begin{abstract}
Nas neuroses traumáticas e de guerra, o ego humano defende-se de um perigo que o ameaça de fora ou que está incorporado a uma forma assumida pelo próprio ego. Nas neuroses de transferência, em época de paz, o inimigo do qual o ego se defende é, na verdade, a libido, cujas exigências lhe parecem ameaçadoras. Em ambos os casos, o ego tem medo de ser prejudicado - no segundo caso, pela libido, e no primeiro, pela violência externa. De fato, poder-se-ia dizer que, no caso das neuroses de guerra, em contraste com as neuroses traumáticas puras e de modo semelhante as neuroses de transferência, o que é temido é, não obstante, um inimigo interno. As dificuldades teóricas que se erguem no caminho de uma hipótese unificadora desse tipo não parecem insuperáveis: afinal de contas, temos todo o direito de descrever a repressão, que está na base de cada neurose, como uma reação ao trauma - como uma neurose traumática elementar. (FREUD, 2010, p. 387-388).
\end{abstract}

Nota-se como o tema se mostra intricado naquele momento para Freud, mesmo porque sua hipótese central sobre a eficácia de um trauma não sexual na neurose traumática vai depois ser descartada em 1926. A diferença na etiologia a partir da noção de dentro e fora é analisada por Freud ao afirmar que é sempre a integridade do Eu que será ameaçada, seja na morte física ou na falência do Eu. Por outro lado, quando Freud faz o trauma equivaler ao recalque originário fundador do psiquismo, dá a ele o lugar estrutural completamente diferente da sintomatologia que resulta do trauma atual, pois neste, há uma repetição inesgotável da cena desencadeante (RUDGE, 2003).

Essa busca por integração irá mais tarde se mostrar insuficiente como tentativa de não reformulação da metapsicologia. A característica falsificadora dos sintomas da neurose traumática, por sua vez, determinará grande reviravolta teórica a partir de 1920, período em que o princípio do prazer deixa de ter um lugar privilegiado no psiquismo, cedendo seu posto à repetição como instrumento pelo qual as experiências traumáticas vão ser aos poucos integradas aos domínios do princípio do prazer. No entanto, há ainda hoje muito o que se refletir acerca de toda essa reformulação metapsicológica em relação à sintomatologia do trauma (RUDGE, 2003).

Tal reformulação efetivada em Além do princípio do prazer por Freud (1920/2006), parece ter encontrado grandes resistências e em busca de uma unificação teórica, Freud é forçado a cada vez mais tratar o trauma como exclusivamente próximo ao trauma infantil. Por outro lado, de acordo com Rudge (2003), este posicionamento deixa a desejar ao

\title{
POLÊM!CA $\mid$ LABORE
}

Polêmica - Revista Eletrônica da Uerj - Rua São Francisco Xavier, 524, $1^{\circ}$ andar

bloco D, sl.1001 • Tels.: +55 21 2334-4088/4087 • http://www.e-publicacoes.uerj.br/index.php/polemica/index http://www.labore.uerj.br • laboreuerj@yahoo.com.br 
entendimento da sintomatologia da neurose traumática, permanecendo sem resposta a questão levantada pela sintomatologia diferente das neuroses espontâneas e traumáticas.

Como exemplo deste abrandamento do alcance da teoria do trauma, em Inibição, sintoma e angústia, ao analisar as prováveis fontes da angústia e de todo afeto, Freud (1926/2014, p. 23) afirma estarmos nos aproximando de uma zona tortuosa por sua contiguidade com a fisiologia e possível afastamento da psicologia. Um jogo de fort-da fundamental ao desenvolvimento da psicanálise, pois por mais que se trate de traumas tão arcaicos:

Os estados afetivos incorporaram-se à psique como precipitados de antiquíssimas vivências traumáticas, e são despertados como símbolos mnêmicos quando situações análogas ocorrem. Quero dizer que não errei ao compará-los aos ataques histéricos, adquiridos depois e de forma individual, e considerá-los modelos normais desses ataques (FREUD, 2014, p. 23).

De fato, o trauma e sua não aceitação como experiência real, de acordo com Caropreso (2006, p. 70), passa a ser associado não mais a "traumas acidentais" da teoria da sedução, mas: "[...] o trauma do nascimento e outras situações que, por se associarem a ele, viriam a adquirir valor traumático. Trata-se, agora, de acontecimentos relacionados ao estado de prematuração e desamparo do ser humano". Passamos, então, de um caráter arbitrário para outro, constitutivo, em relação ao trauma.

Seguindo essa via de análise, questiona-se a ênfase em questões atuais que dificilmente seriam suportadas pela maioria das pessoas, dirigindo-se atenção apenas a conflitos e vulnerabilidades forjadas na infância. Na realidade, a experiência sexual infantil, por ser em psicanálise estruturante do psiquismo, certamente tem seu papel na forma como cada um reagirá a eventos traumáticos.

No entanto, um trauma e sua expressão sintomática - que ocorre após grandes catástrofes ou pelo acometimento de uma séria enfermidade - somente devem ser analisados em razão da experiência sexual? Para dar conta desta problemática, das relações entre trauma e pulsão, é fundamental que passemos por alguns pontos teóricos acerca deste último conceito.

\section{“O 'mais além' que nos atinge... De perto"}

\section{POLÊM!CA $\mid$ LABORE}


É com a publicação de Além do princípio do prazer (1920/2006) que Freud apresenta sua segunda e nova teoria sobre as pulsões. O dualismo pulsional apresentado em 1915 entre pulsões do Eu/autoconservação X pulsões sexuais surge agora entre pulsões de vida X pulsões de morte.

Os comentadores de Freud assinalam que após a publicação de Além do princípio do prazer e a inclusão definitiva do conceito de pulsão de morte houve uma evolução nas ideias freudianas, a saber: em relação à angústia, à sexualidade feminina, à agressividade, à tópica psíquica, etc. "Com a introdução do conceito de pulsão de morte, tudo se modifica, e o campo psicanalítico, até então todo ocupado pela ordem, dá lugar ao caos, ao acaso, transformando por consequência a própria prática psicanalítica” (GARCIA-ROZA, 1999, p. 157).

Inicialmente Freud apresenta a ideia que sempre foi defendida na psicanálise acerca da importância do princípio do prazer na vida psíquica do sujeito. Quando ocorre um acúmulo de tensão aparece o desprazer. Contudo, seria o princípio do prazer dominante? Freud responde negativamente baseando-se na experiência (FREUD, 1920/2006, p. 137).

Posteriormente, Freud comenta a importância do princípio de realidade em relação à obtenção do prazer. As pulsões de autoconservação do Eu, submetidas ao princípio de realidade, devem postergar sua satisfação. Isto causa uma experiência de desprazer.

Além do princípio da realidade, Freud aponta mais outra fonte de desprazer, “originase dos conflitos e clivagens próprios ao processo de desenvolvimento do $\mathrm{Eu}$ em direção a organizações psíquicas mais complexas" (idem, p. 138). Neste caso, Freud está se referindo à ação recalcadora do Eu que não permite a obtenção da satisfação direta das pulsões sexuais.

Sendo assim, vemos, então, que logo de início são incorporados no texto os argumentos encontrados na primeira teoria das pulsões quanto à pressão, fonte, meta e objeto das pulsões, assim como o conceito de recalcamento e sexualidade.

Mais adiante, ele expõe a questão da 'neurose traumática' que deve ser considerada diferente da de angústia porque está mais relacionada com o susto e não com o medo (Angst). O paciente com a neurose traumática é acometido de sonhos que o fazem despertar com susto. "O doente estaria, por assim dizer, psiquicamente fixado no trauma" (idem, p. 140).

Mas os sonhos até então não tinham sido apresentados como uma realização de desejo? Como coaduná-los com vivências traumáticas? Não haveria algumas "enigmáticas

\section{POLÊM!CA $\mid$ LABORE}


tendências masoquistas do Eu" (idem, ibidem) em ação? Em outras palavras, Freud já está perguntando, não estamos lidando com algo da ordem além do princípio do prazer?

Em seguida, Freud interroga o leitor durante muito tempo, apresentando inclusive a famosa e conhecida brincadeira do fort- $d a$ onde a criança joga o carretel de madeira enrolado em um cordão por cima da cama, repetindo o jogo de desaparecimento e retorno repetindo uma experiência prazerosa e desprazerosa.

Após isso, discorre, principalmente, acerca da compulsão à repetição que traz sofrimentos quase dramáticos e calamitosos à vida das pessoas em geral, assim como dos pacientes, que interfere no tratamento observado na transferência. Caropreso e Simanke (2006) ressaltam como a experiência de clínica de Freud legitimou sobremaneira a sustentação da afirmação de uma compulsão à repetição. Segundo os autores

\begin{abstract}
Os neuróticos repetem assim experiências afetivas que, mesmo quando ocorreram, produziram desprazer. Trata-se de pulsões que estavam destinadas a conduzir à satisfação, mas cuja ação produziu apenas desprazer, diz Freud. Apesar de tais experiências terem fracassado em sua meta original, uma compulsão impõem sua repetição. Além disso, a mesma compulsão à repetição dos neuróticos pode ser encontrada na vida de pessoas normais, nos fenômenos chamados por Freud de 'compulsão de destino' (CAROPRESO, SIMANKE, 2006, p. 218).
\end{abstract}

Desta forma, observa-se, outrossim, a importância da escuta clínica de Freud para a construção da formulação de uma 'compulsão à repetição', pois foi mediante o acompanhamento dos tratamentos psicanalíticos que ele constatou a compulsão que se opunha ao prazer. Compulsão que ele chamou até de 'demoníaca'.

Kimmerle (2000) faz notar que Freud não apresenta uma compulsão à repetição de forma 'pura' em sua manifestação. Esta aparece mesclada com o lado aprazível tanto existente no jogo (Fort-da) quanto no mecanismo da transferência.

Freud conduz essa ambiguidade para o fato de que a manifestação da compulsão à repetição nunca é pura, mas aparece sempre associada a outros motivos. Essa constatação vale sobretudo para o jogo infantil, em que a compulsão à repetição misturasse com a vivência pulsional aprazível. Mas também se origina nos fenômenos da transferência, uma vez que a compulsão à repetição do eu reprimido se atém ao princípio de prazer serve à resistência. Mesmo a compulsão de destino e os sonhos de infortúnio não podem ser compreendidos apenas pela compulsão à repetição (KIMMERLE, 2000, p. 80).

Além disso, o que se pode dizer da fatalidade existente na vida de tantas pessoas que parecem viver passivamente perante situações da vida que lhe causam sofrimento e que

\title{
POLÊM!CA $\mid$ LABORE
}


colocam em um círculo vicioso amoroso de dor e sofrimento? Após estas pontuações Freud conclui:

\footnotetext{
Ao levarmos em conta essas observações a respeito da transferência e a fatalidade presente no destino de tantos seres humanos, vemo-nos encorajados a assumir a hipótese de que realmente existe na vida psíquica uma compulsão à repetição que ultrapassa o princípio de prazer. (FREUD, 1920/2006, p. 148).
}

Mas qual seria a relação então entre o que é pulsional e a compulsão à repetição? Freud conclui que o organismo tende a voltar a um estado anterior e que uma "pulsão seria, portanto, uma força impelente interna ao organismo vivo que visa a restabelecer um estado anterior que o ser vivo precisou abandonar devido à influência de forças perturbadoras externas" (grifos do autor, idem. p. 160). Mais adiante, Freud afirma: “[...] então podemos dizer que $O$ objetivo de toda vida é a morte, e remontando ao passado: o inanimado já existia antes do vivo". (grifos do autor, idem, p. 161).Vemos aqui o trágico como elemento fundante da psicanálise, isto é: a finalidade da vida é a morte - e, importante ressaltar que não se trata de um "pessimismo", mas que desta causa aparentemente perdida, algo pode ser feito por cada sujeito em busca de sua salvação (FREUD, 1929[1930]/1996).

Freud nomeia a libido de Eros: "a libido de nossa teoria sexual coincidiria com o Eros dos poetas e dos filósofos que mantém unido tudo que é vivo" (idem, p. 172) e continua a utilizar em sua argumentação a metáfora biológica para explicar sua metapsicologia. Os movimentos de união das células em unidades maiores apontam para a vida e trabalham no sentido de neutralizar o poder das pulsões de morte que tendem a levar o organismo a retornar ao inorgânico.

Mais adiante, Freud passa a comentar sobre o seu primeiro dualismo pulsional de 1915 e assinala que àquela época entendia que se tratava de um dualismo entre pulsões sexuais e pulsões do Eu. Acontece que com o conceito de narcisismo, o Eu passou de ser considerado apenas como instância recalcadora responsável pela censura. (idem, p. 173)

A libido que se aloja no Eu é a 'libido narcísica'. Desse modo, aquelas pulsões de autoconservação tem, por conseguinte, caráter libidinal. Rudge (1998) ressaltou a importância do conceito de narcisismo para a transposição da primeira para a segunda teoria das pulsões. Isto porque, sendo o Eu também reservatório da libido, uma parte das pulsões do Eu era também sexual. "O principal dos motivos da mudança seria que o narcisismo marcou um

\section{POLÊM!CA $\mid$ LABORE}


momento de fracasso na perspectiva dualista, tornando necessária a virada que reconstitui o dualismo de forma diferente" (idem, p. 33).

Já no Além do princípio do prazer, Freud apresenta um dos indicativos da pulsão de morte - o sadismo. Segundo ele, "desde o início havíamos reconhecido a existência de um componente sádico na pulsão sexual" (FREUD, 1920/2006, p. 174) e mais adiante afirma que anteriormente foi levado a concluir que o masoquismo seria uma "pulsão parcial complementar ao sadismo" (idem, p. 175). O sadismo, mais precisamente neste texto, seria a expressão da pulsão de morte, mas que se funde com a pulsão sexual. Esta, direcionada ao objeto, depois de um processo regressivo, tem conotações destrutivas.

É ressaltado ainda no Além... por Freud que não há uma pulsão em estado original, mas sim uma mistura, ou melhor, uma fusão e defusão pulsional. Conceito este que Freud apresentará mais detalhadamente em O problema econômico do masoquismo de 1924. (Cf. FREUD, 1924/2007, p. 109). Contudo, fica claro em 1920 que Freud aponta o sadismo como um dos indicativos da pulsão de morte, fazendo eco a uma observação que sempre lhe foi presente, que era a constatação da agressividade juntamente com a expressão da sexualidade.

Quase no final de seu texto Além do princípio do prazer, Freud reafirma que a trilha que o levou à pulsão de morte foi a compulsão à repetição e que, em relação à vida psíquica, entende a pulsão de morte como uma tendência dominante.

\footnotetext{
Nesse sentido, um dos motivos mais fortes para acreditarmos na existência das pulsões de morte reside em nossa concepção de que a tendência dominante da vida psíquica, ou talvez da vida nervosa em geral, seja, tal como expressa o princípio do prazer, o anseio por reduzir, manter constante e suspender a tensão interna provocada por estímulos (o princípio de Nirvana, segundo uma expressão de Barbara Low [1920,73]. (FREUD, 1920/2006, p 176).
}

No entanto - e como aqui se observa -, se é em caráter preliminar que Freud (1920) ainda se refere à pulsão de morte, no Mal-estar na civilização (1929[1930]/1996), Freud já se mostra bem mais convencido de sua teoria. Nesta, Freud analisa a questão da agressividade e relembra que não era tão simples identificar a manifestação da pulsão de morte, pois enquanto Eros é facilmente percebido em sua ruidosa presença, Thanatos é silencioso. Nesse sentido, já que Eros atua numa tendência à conservação da vida, poder-se-ia afirmar que ele escapa à tendência universal da repetição? Nas palavras de Mezan:

\section{POLÊM!CA $\mid$ LABORE}


Nada mais falso: uma vez seguida, a vida tende também a se repetir, e a função de Eros é assegurar a reiteração indefinida do ciclo vital, protegendo da tendência regressiva às células portadoras do plasma germinativo, até que, cumprida a finalidade reprodutora e destacado do soma o germe que vai assegurar a preservação da espécie, aquele possa sucumbir à pulsão de morte sem maior dano para a natureza (MEZAN, 1985, p. 443).

Como se perceberia, então, a pulsão de morte? Freud responde que "uma ideia mais fecunda era a de que uma parte do instinto [da pulsão] é desviada no sentido do mundo externo e vem à luz como um instinto de agressividade e destrutividade" (FREUD, 1929[1930]/1996, p. 123). Nesse movimento de desagregação da pulsão de morte, ela somente se apresenta visível em forma de repetição (na clínica), e pela severidade do supereu, no masoquismo originário, no ódio e no sadismo (no psiquismo) (MEZAN, 1985).

Laplanche (1985) afirma que Freud somente desenvolveu uma teoria da pulsão agressiva depois de 1920, apesar de ter exposto em vários textos anteriores de sua obra a importância da agressividade, do ódio e do sadomasoquismo; como pode ser averiguado, por exemplo, em Pulsão e destinos da Pulsão (1915/2004). O autor destaca ainda que o importante na questão do desenvolvimento da pulsão agressiva, após 1920 , foi o fato de a agressividade estar:

[...] voltada primeiro para o sujeito e como que estagnada nele, antes de ser dirigida para o exterior - o termo "sujeito" compreendido aqui em todos os níveis, tanto o ser biológico multissecular e, evidentemente, tanto o indivíduo humano considerado como individualidade biológica, quando como 'vida psíquica' (LAPLANCHE, 1985, p. 90).

Ao percorrer os textos acima expostos de Freud, vemos que a segunda teoria das pulsões, de fato, é utilizada por ele como fundamento de várias de suas argumentações teóricas. A importância da teoria pulsional foi mesmo reconhecida por Freud que nas suas Novas conferências introdutórias, conferência XXXII (Ansiedade e Vida Instintual) (1933) chamou-as, inclusive, de "nossa mitologia” (FREUD, 1933/2010, p. 241).

Este pequeno arrazoado sobre a teoria pulsional deve nos servir de apoio para os desafios na clínica psicanalítica que atualmente continua apresentando repetições, sofrimentos e, principalmente, problemas relacionados ao sentimento de culpa que tem um nexo diretamente proporcional com a agressividade e pulsão de morte.

\section{Trauma, pulsão e HIV/Aids}

\section{POLÊM!CA $\mid$ LABORE}


Se, como vimos, o aparelho psíquico é provido de representações armazenadas na finalidade de resguardá-lo do excesso de estímulos internos e externos - os primeiros excessos, constantes e traumáticos, exigindo elevada atividade de simbolização; os externos, por sua vez, constituindo a elevada exigência de satisfação pulsional - então, temos aí uma dupla e árdua tarefa. Se somarmos a este conjunto alguns elementos que pegam carona no imaginário da Aids em nossa cultura - Aids como sentença de morte e como doença que somente acomete aos "desvairados" -, temos um quadro extremamente intrincado.

$\mathrm{Na}$ dissertação realizada por Francês e Bacchini (2016), notam-se algumas características intrigantes relacionadas ao diagnóstico e à forma como este é comunicado ao paciente, pois parece haver uma reatualização de um trauma primitivo que faria o sujeito reviver sua condição de desamparo. No que diz respeito ao trauma, o diagnóstico de HIV/Aids pode ser sentido como algo impossível de se representar. Nas palavras de Rudge (2003, p.113):

\begin{abstract}
A falta de recursos para lidar com certos acontecimentos jamais é inteiramente superada. Pode-se ser reconduzido a uma situação de desamparo em qualquer momento da vida, e não apenas como consequiência do acosso pelas pulsões insatisfeitas, mas também dos golpes dolorosos do destino, doenças, perdas, violências e traições a que estamos sempre sujeitos, e que muitas vezes significam um grave golpe no narcisismo [...] Os recursos simbólicos de que dispomos para lidar com o que a vida pode nos apresentar não são ilimitados. O vazio de razões, a falta de preparação, a impossibilidade de dar qualquer sentido para um acontecimento doloroso, nos remetem a uma posição de impotência para responder a ele e o caracterizam como traumático (RUDGE, 2003, p.113).
\end{abstract}

A noção sobre o trauma até aqui descrita, evidencia as inúmeras possibilidades de se tratar das representações as quais o paciente com Aids pode revelar, pois parece haver uma via de comunicação bastante próxima entre a sintomatologia anímica destes pacientes e o trauma. O relato trazido inicialmente de forma proposital, tenta viabilizar tal comunicação, pois não se trata de um caso isolado, mas de uma repetição em que pacientes, ao receberem seu diagnóstico, apresentam uma fixação tanto no evento do diagnóstico quanto em situações relacionadas: possível experiência sexual pela qual se deu o contágio, pensamentos obsessivos acerca de sua enfermidade e sonhos recorrentes em que o tema da morte emerge.

\title{
Considerações finais
}

Finalizamos com um relato ocorrido no mesmo hospital: "Doutor, eu tenho muito medo de sair daqui mancando, de dar vexame na rua da minha casa [...]". Ela dizia isso com

\section{POLÊM!CA $\mid$ LABORE}

Polêmica - Revista Eletrônica da Uerj - Rua São Francisco Xavier, 524, $1^{\circ}$ andar

bloco D, sl.1001 • Tels.: +55 21 2334-4088/4087 • http://www.e-publicacoes.uerj.br/index.php/polemica/index

http://www.labore.uerj.br • laboreuerj@yahoo.com.br 
frequência, até que conseguiu trazer mais elementos de seu medo a partir de um sonho. Nele, ela se via repleta de baratas e insetos que cresciam aos montes sem que ela pudesse ter algum controle ou escapar. Foi então que ela me falou: "Parecia que eu 'tava' num cemitério!”.

O trauma do modo que é aqui tratado, não constitui relação apenas com o "só depois" entre o recalcado e o acontecimento atual. Este trauma do qual nos referimos não se apoia no recalcado, mas sinaliza um vazio diante da impossibilidade de dar sentido ao que se faz presente. Afinal, como dar sentido a uma síndrome gravíssima e recentemente diagnosticada (uma vez que ela [ainda] não possui cura)? Seria possível ao Eu a representação do irrepresentável da iminência de morte orgânica aliada à possibilidade de uma morte social? Poderia haver preparação frente à angústia de se haver contaminado pelo vírus do HIV/Aids? Novamente, como afirma Rudge (2003):

É este vazio que não permite caracterizar teoricamente o trauma apenas pelas qualidades do acontecimento que surpreendeu dolorosamente o sujeito. $\mathrm{O}$ valor traumático do acontecimento é relativo a um determinado psiquismo, e, portanto, regido não apenas pelas qualidades do fato, mas também pela história do sujeito. $\mathrm{O}$ que a história justifica é a impossibilidade de antecipar ou de integrar um evento, como algo dotado de uma significação que possa se articular às narrativas que o sujeito se dá de si mesmo e do mundo em que vive. Por isto mesmo, o sintoma assume a feição de uma interminável repetição, em que a tentativa de integrar o corpo estranho que é o acontecimento traumático vivido, à própria história, é o móvel dominante (RUDGE, 2003, p. 114).

Freud (1926/2014), portanto, leva em consideração tanto um caráter traumático do real do nascimento e, com isso, a escuta destes pacientes se mostra fundamental na medida em que, não somente tem se tornado cada vez maior o número de pessoas vivendo com Aids, mas as possibilidades de escuta e de desenvolvimento teórico a partir dessa interlocução se mostram férteis.

A situação do conflito psíquico, por sua vez, remete sempre à questão de que no discurso do sujeito aparecerá a contradição, o sofrimento, a incerteza, a oposição de sentimento, etc. O conflito aponta, outrossim, para o fato de que o discurso do sujeito também surja dentro da lógica da contradição, isto porque está imerso da lógica inconsciente e das pulsões.

Aqui é fundamental marcar a possibilidade que se faz presente no que diz respeito ao trauma do diagnóstico de Aids aqui discutido. Isto, pois a escuta nos ambulatórios e enfermarias do hospital parece proporcionar ao indivíduo hospitalizado a possibilidade de colocar em discurso algo em torno daquilo que se revelou sem sentido, exatamente pelo

\section{POLÊM!CA $\mid$ LABORE}

Polêmica - Revista Eletrônica da Uerj - Rua São Francisco Xavier, 524, $1^{\circ}$ andar

bloco D, sl.1001 • Tels.: +55 21 2334-4088/4087 • http://www.e-publicacoes.uerj.br/index.php/polemica/index

http://www.labore.uerj.br • laboreuerj@yahoo.com.br 
inassimilável de seu excesso - afinal, encontrar-se portador de uma síndrome atravessada culturalmente por preconceito e morte, tange o inominável.

Com efeito, é na escuta que se observa as várias manifestações tanto da pulsão de vida quanto da pulsão de morte. Vemos, por exemplo, como se desenvolve o sentimento de culpa que já é um anteparo ao real, diante disso que se mostra inassimilável num evento traumático - em O Problema Econômico do Masoquismo quando Freud expôs a questão do masoquismo moral. "O sofrimento é que importa" (FREUD, 1924/2007, p. 111) diz Freud, o que culmina em uma necessidade de sofrimento por parte do paciente, inclusive ocasionando a relação terapia a conhecida 'relação terapêutica negativa'.

Todas essas são manifestações da pulsão de morte que se mostram pelo sofrimento dos pacientes. A ação de um Supereu que age de forma agressiva contra o Eu deve sempre chamar a atenção do psicanalista, pois entendemos que é uma das formas possíveis de se pôr o sofrimento em discurso. O presente estudo trata então, de um recorte dessa realidade, ou melhor, do que foi possível presenciar na escuta desses pacientes a partir do que foi desenvolvido aqui sobre o conceito de trauma e sua possibilidade de articulação com um dos conceitos fundamentais em psicanálise: a pulsão.

\section{Referências}

CAROPRESO, Fátima; SIMANKE, Richard Theisen. Compulsão à repetição: um retorno às origens da metapsicologia freudiana. Ágora, Rio de Janeiro, v. IX, n. 2, p. 207-224, jul/dez. 2006.

FRANCÊS, I.; BACCHINI, A. M. "Que é que os homens temem, acima de tudo?”. Culpa e vergonha na clínica da Aids. Polêm!ca, Rio de Janeiro, v. 16, n.1, p. 22-33, jan.-mar. 2016.

FREUD, S. Pulsão e destinos da Pulsão (1915). In: HANS, Luís Alberto (coord.). Escritos sobre a psicologia do inconsciente. Rio de Janeiro: Imago, 2004.

Conferência XVIII: A fixação no trauma - o inconsciente (1916). In: Edição standard

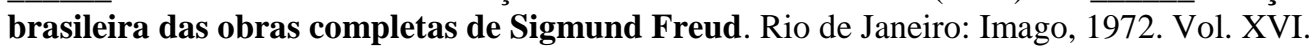

Introdução a psicanálise das neuroses de guerra (1919). In: . Obras completas. São Paulo: Companhia das Letras, 2010. Vol. 14.

Além do princípio do prazer. (1920). In: HANNS, Luiz Alberto (coord.). Escritos sobre a psicologia do inconsciente. Rio de janeiro: Imago, 2006. p 123-198.

O problema econômico do masoquismo (1924). In: HANNS, Luiz Alberto (coord.). Escritos sobre a psicologia do inconsciente. Rio de janeiro: Imago, 2007. p 103-124. 2014. Vol. 17 .

\section{POLÊM!CA $\mid$ LABORE}


O mal-estar na civilização ([1929]1930). Edição standard brasileira das obras completas de Sigmund Freud. Rio de Janeiro: Imago, 1996. Vol. 21.

Novas conferências Introdutórias (1933). In: Obras Completas. vol. 9. Trad. Paulo César de Souza. 12a Ed. São Paulo: Companhia das letras, 2010.

GARCIA-ROZA, Luiz Alfredo. Introdução à metapsicologia freudiana - 3. Rio de janeiro: Zahar, 1999.

KIMMERLE, Gerd. Denegação e retorno: uma leitura metodológica de "Para além do princípio de prazer" de Freud. Trad. Osmyr Faria Cabbi Jr. Piracicaba: Ed. UNIMEP, 2000

LAPLANCHE, J. Vida e morte em psicanálise. Trad. Cleonice Paes Barreto Mourão e Consuelo Fontes Santiago. Porto Alegre: Artes Médicas, 1985.

LAPLANCHE, J.; PONTALIS, Jean-Bertrand. Vocabulário de Psicanálise. Trad. Pedro Tamen. $3^{\text {a }}$ ed.. São Paulo: Martins Fontes, 1998.

MEZAN, Renato. Freud, o pensador da cultura. 5a ed. São Paulo: Ed. Brasiliense, 1985.

RUDGE, Ana Maria. Trauma. Rio de Janeiro: Jorge Zahar Ed., 2009.

Trauma e temporalidade. Rev. Latinoam. Psicopat. Fund., ano VI, n. 4, p. 102-116, dez. 2003.

Pulsão e linguagem. Esboço de uma concepção psicanalítica do ato. Rio de janeiro: Ed. Zahar, 1998.

Recebido em: 29/01/2017.

Aceito em: 30/03/2017.

\section{POLÊM!CA $\mid$ LABORE}

